\title{
Code, Culture, and Concrete: Self-Driving Vehicles and the Rules of the Road
}

\author{
Chris Tennant ${ }^{1 \star t}$, Chris Neels ${ }^{2 \dagger}$, Graham Parkhurst ${ }^{3}$, Peter Jones ${ }^{1}$, Saba Mirza ${ }^{1}$ and \\ Jack Stilgoe ${ }^{1+}$ \\ ${ }^{1}$ Science and Technology Studies, University College London, London, United Kingdom, ${ }^{2}$ Other, Vancouver, BC, Canada, \\ ${ }^{3}$ Centre for Transport \& Society, University of the West of England, Bristol, United Kingdom
}

OPEN ACCESS

Edited by:

Mark Lemon,

De Montfort University,

United Kingdom

Reviewed by:

Andrew Mitchell,

De Montfort University,

United Kingdom

Muhammad Mazhar,

Nottingham Trent University,

United Kingdom

${ }^{*}$ Correspondence:

Chris Tennant

c.tennant@ucl.ac.uk

†These authors share first authorship

Specialty section:

This article was submitted to

Governance and Cities,

a section of the journal

Frontiers in Sustainable Cities

Received: 27 May 2021

Accepted: 20 October 2021

Published: 18 November 2021

Citation:

Tennant C, Neels C, Parkhurst G, Jones P, Mirza S and Stilgoe J (2021)

Code, Culture, and Concrete:

Self-Driving Vehicles and the Rules of

the Road.

Front. Sustain. Cities 3:710478.

doi: $10.3389 /$ frsc. 2021.710478
Behaviour on the road is ordered by a range of norms, rules, laws, and infrastructures. The introduction of self-driving vehicles onto the road opens a debate about the rules that should govern their actions and how these should be integrated with, or lead to the modification of, existing road rules. In this paper, we analyse the current rules of the road, with a particular focus on the UK's Highway Code, in order to inform future rulemaking. We consider the full range of laws, norms, infrastructures, and technologies that govern interactions on the road and where these came from. The rules have a long history and they contribute to a social order that privileges some modes of mobility over others, reinforcing a culture of automobility that shapes lives, livelihoods and places. The introduction of self-driving vehicles, and the digital code on which they depend, could reorder the culture and concrete of our roads, by flattening the multidimensional rules of the road, hardening rules that are currently soft and standardising across diverse contexts. Future rule changes to accommodate self-driving vehicles may enable increases in safety and accessibility, but the trade-offs demand democratic debate.

Keywords: digital highway code, legal pluralism, automated vehicles, self-driving cars, rules, governance

\section{INTRODUCTION: A DIGITAL HIGHWAY CODE?}

Do the rules of the road need to change to accommodate the introduction of autonomous vehicles ("AVs"), and who should decide upon any such changes? This paper combines a literature review with an analysis of the history and politics of road rules to ask what is at stake in changing the rules of the road. Our analysis was prompted by conversations during some of our research interviews ${ }^{1}$, in which we discussed the challenges faced in formulating rules for a road network to be shared by human drivers and AVs.

One computer scientist working for a self-driving car company expressed the question as, "How can you formalise in a crisp way, in a way that you can code to an autonomous car, all the unwritten rules of the road?" He was convinced that his company could, in his words, "solve the safety problem" caused by erratic human drivers, but in order to do so, they would first have to

\footnotetext{
${ }^{1}$ The Driverless Futures? project included more than 50 qualitative interviews with people involved in self-driving technology. Sixteen interviewees worked in research and development at self-driving technology companies; 11 were technologists in academic positions; six were from car companies. The rest were academic researchers, policymakers and other stakeholders. 22 were from North America and 27 were from Europe. These interviews are analysed in more depth in (Stilgoe, 2021; Tennant and Stilgoe, 2021). Material from three of these interviews is used solely in the introduction to illustrate the questions posed by this paper.
} 
demonstrate that their robot cars obeyed the law. However, the law seemed threadbare: "If you redesigned all the transportation systems from scratch, then you would do many things differently... What we found out when working on [our model] is that the law... is incomplete." The interpretation of rules around, for example, who is liable in a crash, often seems to be worked out after the fact: "you cannot work like this in a robotic car. Tell me in advance!” The rules of the road, according to this engineer, were sometimes illogical and often broken by drivers. The rules that would govern his cars' actions would, he claimed, ensure that his technologies were safe, but they could also rationalise the road and its other users. "These systems educate people," he said, "if these [new] rules are good, why wouldn't we change the law to follow these rules?"

As interest and investment in driverless technologies has grown in the last 15 years, an origin story that lauds the pioneering efforts of contestants in the US military funded Darpa Grand Challenges of 2002-2007 (Burns and Shulgan, 2018) has overshadowed a longer, more complicated history of automotive automation (Wetmore, 2003). As technology companies manoeuvre their vehicles beyond imagined futurescapes and desert landscapes, they must contend with roads as unavoidably social spaces, on which a variety of travellers move and interact. These travellers are governed by laws, norms and material constraints that do not straightforwardly translate into algorithms. At the time of writing, prototype self-driving vehicles are being tested in cities and on highways in the US, Europe, China and elsewhere. One of the leading companies, Waymo, are operating driverless taxis on public roads in a part of Phoenix, Arizona when the weather is good. Meanwhile, Tesla sells "full self-driving" as an upgrade to their new cars, although their technology is actually a form of advanced driver assistance. Our research has sought to understand the futures that are being imagined around the technology and anticipate the emerging political ramifications. The hype about the technology's benefits is enormous, but this has been accompanied by concern about the risks of robots on the road and the questions of responsibility that might emerge, so that the arguments presented for and against self-driving vehicles have shifted over time as greater detail about the technical prospects has become evident. Much of the debate about the ethics of self-driving vehicles (e.g., Nyholm and Smids, 2016; Awad et al., 2018; Bonnefon et al., 2019) started from an assumption that the technology will be able to see more clearly, plan more rationally, and make better decisions than any human. This misrepresents not just the technology but also the nature of on-road interactions, which are interdependent (Domeyer et al., 2020). Self-driving cars have become a high-profile test case for artificial intelligence in the wild, but companies' early experiments have shown them how much of driving is governed by the sort of common sense that is hard to programme.

A second interviewee from another self-driving company was frustrated that "We don't have a formal notion of what it means to be a good driver," while another, a machine learning researcher, described the challenge like this:

\footnotetext{
"Driving, it's like, Okay, here are the rules. I have them in this, you know, 20 page booklet, the California driver's manual, or whatever.
}

And, you know, it's not supposed to be that hard. But it is, right?... Billions of dollars have been invested [in self-driving technology] and billions of miles have been collected and it turns out that it is hard. Part of that is because the simple statement of the problem hides the complexity of the real world. So there is nothing in the driver's handbook about what to do [about] people crossing the street on a skateboard."

If we expect self-driving vehicles to follow the rules of the road, which rules do we mean? Regulators are now under pressure to come up with rules that fit the needs of self-driving vehicles. Writing together with a company developing self-driving cars, one group of researchers called in 2019 for "a publicly-available, machine-readable and complete set of... traffic laws and driving codes and conventions, a Digital Highway Code" (McDermid et al., 2019). This would clarify when to cross a central dividing line to avoid lane obstructions, whether it is acceptable to mount the pavement/sidewalk, when to pass through defective traffic lights and how to deal with other situations in which human drivers are forced to improvise. The idea of updating and digitising the rules of the road seems on the face of it logical, not just for the developers of self-driving vehicles. It could be an opportunity to organise, to clarify and potentially to correct some of the hazards and injustices that characterise mobility. For example, it would be possible to enforce, for the first time, quantitatively defined minimum following or passing distances.

Western governments are enthusiastically embracing the prospect of self-driving vehicles both to address the current downsides of mobility and to capture some of the economic benefits of innovation. However, we should ask what is at stake in the rewriting of road rules to suit a new technology. Over the course of the 20th century automobility has reordered society (Urry, 2004). Rules that favoured cars were imposed upon others often with limited debate (Norton, 2008). Even if only a fraction of the many promised transformations of self-driving vehicles are realised, we could see in this century a profound reconfiguring of road behaviours, roads, places and lifestyles. The debate about rules for self-driving cars can and should be more democratic. Otherwise, the risk is that code will colonise our culture and our concrete.

In this paper, we examine how different types of rules currently govern road uses and road users. Following this, we analyse some tensions, questions, and challenges that policymakers, AV developers and the public will need to negotiate as they converge on a new set of rules. Future conversations involving digital codes, highway codes, car cultures and the material infrastructures of the road look set to be hugely consequential and controversial. At the time of writing, such conversations are just beginning, and they are taking place in the rarefied language of technological standards. This paper outlines the social issues that are likely to be pertinent in opening up a discussion of the future rules of the road.

\section{RULES IN THEIR SOCIAL CONTEXT}

\section{Norms, Rules, and Laws}

To consider the road rules of the future we start with the rules of the present. Behaviour on the road can be seen as governed 
by rules in four layers: the laws of physics can be seen as constraints on what you can and cannot do; legal rules define what you must and must not do; advisory guidance shapes what you should and should not do; and then there is a layer of social norms and behaviours: what we tend to do and not do. These layers overlap. Many of our social norms align with the rules of the other layers. However, there are also gaps, conflicts and tensions within the multiple layers that are typically managed through road users' common sense, by the police or in court.

This state of affairs is typical of "living law," a concept first advanced by Ehrlich to describe how actual behaviour is ordered by multiple, overlapping systems of rules and laws rather than a monolithic national legal system (Nelken, 2008). Early studies of "legal pluralism" examine how colonising imperial legal systems subordinated, or co-existed with, local customs or the norms deriving authority from faith or other group memberships (Benda-Beckmann and Turner, 2018). Others, such as Ellickson (1991) or Moore (1973) conducted anthropological field studies to show how social groups developed their own norms and their own systems of conflict resolution. Moore proposed the concept of a "semi-autonomous social field," which "has rule-making capacities, and the means to induce or coerce compliance; but it is simultaneously set in a larger social matrix which can, and does, affect and invade it" (Moore p 720). Norms and rules can conflict and collective norms can be used as modes of resistance to top-down rules. This resistance can be ironic, as when staff "work-to-rule," following the letter rather than the spirit of their contracts, in order to protest wages or conditions, revealing "a host of informal practises and improvisations that could never be codified" (Scott, 1998; p. 6). Fish (1984, p. 1330) concludes that "no set of rules could be made explicit enough to cover all the possible situations that might emerge within a field of practice," the interpretation of which requires tacit knowledge. The road is one example of a system where, following Wittgenstein, we can see that rules underdetermine action. And the responsibilities that we expect of others transcend rules (Richardson, 1999): when we learn to drive, we know that it is a process of enculturation and skill-development, not just rule-learning.

A range of authors consider how norms of behaviour in daily social interactions compare to the legal provisions covering the same activities (e.g., Reisman, 1999; Jutras, 2001). These analyses help explain the brief encounters we have on the road, but Jutras argues that we should not treat the implicit rules that often govern our behaviour-e.g., allowing someone else to join a flow of traffic even though you have the right of way-as if they are laws. Nelken (ibid) points out that although these accounts describe well how we order our daily interactions, semi-autonomous social fields presuppose the existence of national laws as a means of recourse in the event that interactions ordered by local norms don't work out.

\section{Rules Encoded}

Technology can be seen as imposing a form of rule-making (Wynne, 1988; Lessig, 2006) or script-writing (see Akrich, 1992; Latour, 1992, 1994). Just as social constructs impose rewards and punishments (Ellickson, 1991; p. 124), technological constructs prescribe and proscribe behaviours or ways of life (Sovacool and Hess, 2017). The regulation of technology is not straightforward, in part because "technology legislates the conditions of human existence" (Winner, 1977; p. 324) in much the same way as formal regulations do. Bruno Latour calls technologies a form of solidified politics: "The engineers' program... inscribed in concrete" (Latour, 1994; p. 38). This applies to digital artefacts as much as concrete ones. For Lessig (ibid), "code is law." We can read some of the politics of roads in the relative space that is given over to different modes of transport, the timings of traffic lights, "traffic calming measures" and crossings. The differences between material and social rulemaking are often most visible when we transgress. As Latour concluded, discussing the sleeping policeman and other simple devices, "no human is as relentlessly moral as a machine" (Latour, 1988; p. 301). Technologies are hard to argue with. For digital technologies, the ramifications may not be so visible but they will be no less profound. As navigation apps, real-time traffic management systems and smart infrastructures are layered onto the road network, some city transport officials have declared, "code is the new concrete" (Sadik-Khan, 2018).

So-called "disruptive innovation" may unashamedly seek to break or reshape established processes through technological change, claiming that the old rules no longer apply. Supranational regulatory processes are typically framed by innovators and dominated by highly specialised "epistemic communities" (Benda-Beckmann and Turner, 2018). This privileged knowledge wields considerable power in international standards-setting. Where once the legal system of the nation state colonised and re-moulded the norms of occupied territories, now rules defined by globalising technologies may colonise, override, and remould those of the nation state.

The idealised promise of artificial intelligence is that it formalises understandings of and interactions with the world to make them more efficient (Stilgoe, 2018). However, we can start to anticipate some of the requirements that will inevitably follow the promises (Van Lente, 2000). For algorithms to make sense of the world, the world needs to be remade such that it makes sense to algorithms. Before we seek to understand how the rules imposed by automated mobility technologies and their proponents might create such requirements, we should first seek to understand the multiplicity of existing road rules.

\section{ORDERING THE ROAD}

\section{Rules for the Road}

We can apply these insights into the nature of rules to the rules developed for the road. The road networks that support modern mobility have been continuously but slowly reorganised to reflect the mobility practices of society, where technologies, competencies and skills evolve as different transport options emerge, and the meanings, or values, placed on practices, such as the owning and driving one's own vehicle, change (Shove, 2012). Hence, the rules governing how road users should move along roads have also evolved to accommodate new modes of mobility, seeking to reconcile the needs of the different transport modes sharing these spaces, but always privileging some over others. The literature on the coexistence of norms and laws suggests we 
should pay attention to several layers of road rules. Some rules are hard and fast, such as licencing regimes; others are soft and wide open to interpretation (Björklund and Åberg, 2005). Some rules are rigidly policed while others, such as speed limits, are clearly stated but subject to wide variations in enforcement. Rules may be mediated by technologies and infrastructures or depend on interpersonal interaction. Lastly, there is a layer of social practice, structured by, and contributing to the structure of, the layers underneath (Shove, 2012). Over time, socio-economic needs for the movement of people and goods together with the vested interests of specific groups can force change in the prevailing ordering of the road, influencing the extent to which rules are enforced, as discussed below.

The different sets of rules are generated by various sources of authority. National laws rest on the authority of the state. Then there are the rules that different groups of road users, such as drivers, cyclists, pedestrians or horse riders, are supposed to follow, whether legally required or only advised, and these may vary between places and types of road. There are norms of road behavior which may pattern urban driving very differently from rural, and subgroups that may be informal (e.g., "boy racers" or "Sunday drivers") or defined by membership (e.g., Institute of Advanced Motorists). There is little agreement on what constitutes a good driver. Car culture has tended to equate "good driving" with an appreciation of vehicle mechanics, and even with an interest in car racing (see Crawford, 2020), rather than just safety. Surveys of drivers suggest that most regard themselves as better than average (Svenson, 1981).

\section{The Emergence of Rules to Order Roads in the UK}

Traffic laws are the predominant mechanism with which governments look to apply order to roads. In the UK, current traffic laws are inextricably rooted in the past. Their introduction has tended to lag behind a realisation of issues stemming from the proliferation of automobiles. Compulsory driving tests were first applied to drivers of public service vehicles in the 1930 Road Traffic Act, gradually rolling out to other drivers following the 1934 Road Traffic Act. The licencing regime sought to build compliance with traffic laws by penalising repeat offenders with disqualification. Vehicle roadworthiness (MOT) tests were introduced in the Road Traffic Act (1988), which also required drivers to ensure their vehicles are in safe condition.

The UK's traditional reliance on etiquette, courtesy, and manners could be seen in the Motor Car Act 1903 and the Roads Act 1920, which prescribed little in the way of governing road behaviours. It was not until the Road Traffic Act 1930-with the first Highway Code published the following year-that rules of the road began to be standardised, by which point public outrage at road deaths, particularly those of children, demanded attention (Moran, 2009). The Highway Code has, from its first publication in 1931 to the current version ${ }^{2}$, promoted common sense and consideration for other road users as the foundation

\footnotetext{
${ }^{2}$ The "current" highway code has a printed version (Driving Vehicle Standards Agency, 2018) as well more recent online updates at https://www.gov.uk/guidance/ the-highway-code. References to clauses in the current version are to that prevailing on October 23, 2020.
}

for responsible road behaviour. The transport minister wrote in the first Code's foreword that it should be seen as "a code of good manners to be observed by all courteous and considerate persons" (Ministry of Transport, 1931; p. 1). The current highway code explains that provisions that "must" be followed "are legal requirements, and if you disobey these rules you are committing a criminal offence" (ibid, p. 4). Rules which "should" be followed are "advisory" (ibid, p. 3). The caveat that breaches of rules that "should" be followed are likely to be evidence against transgressors in the event of a consequent dispute that comes to court softens, but does not eliminate, the distinction. The advisory layer overlaps not only the legal layer, it also overlaps the normative layer, since it explicitly writes down the injunctions of an unwritten code of good manners.

Drivers are expected to apply discretion to stay aligned with the law. Many country roads in the UK have no speed limit signs. The law technically prescribes default maximum speeds, but drivers are expected to reduce speed based on road and weather conditions, and on the presence of surrounding road users (Highway Code 125). If drivers are deemed to deviate from careful behaviours, they could be prosecuted for driving without due care and attention-an offence that also involves interpretative discretion. Non-compliance with traffic laws is considered to be necessary sometimes to protect drivers or others or avoid the obstruction of traffic. Drivers are expected to make judgements that might be transgressive when, for example, allowing emergency vehicles to pass, although the Highway Code (219) says drivers should "avoid mounting the kerb." Other road users, such as cyclists (Latham and Nattrass, 2019) and motorcyclists (Qian, 2014), may interpret the rules in their own ways, leading to transgressions of a different sort and accusations of unruliness from drivers. When accidents occur and harm is suffered, the obligation to exchange identification details or to inform the police formalises the process (Section 170 of the Road Traffic Act, 1988). Common sense is not fixed. Norms can be influenced by regulations or they can become inscribed into laws or even infrastructures. For example, conventions for passing other vehicles on one side or the other became, over time, rules and then design briefs for roads and their junctions (Young, 1996).

After World War 2, changes to traffic laws tended to follow increases in road deaths, which reached an annual peak of 7,985 in Great Britain in 1966 (Keep and Rutherford, 2013) ${ }^{3}$. A speed limit of $30 \mathrm{mph}$ in urban areas was introduced in 1934 (reversing legislation from 1930 that removed speed limits). The Road Traffic Regulation Act of 1967 brought in drink drive limits and offences of reckless, dangerous, and careless driving, which were followed in the Road Traffic Act 1972 by the formalisation of a legal obligation to comply with the rules communicated by traffic signs. Some laws were more clearly targeted at protecting people in cars from themselves and each other. Installing seat belts became mandatory in 1968, but it was not until 1983 that drivers and front seat passengers were compelled to wear them. As with other improvements to driver safety, this may have led

\footnotetext{
${ }^{3}$ Strategies for road safety improvement are typically attributed to a mix of the "three Es": engineering, enforcement and education (Gains et al., 2004).
} 
to increased danger for others on the road through drivers' risk compensation (Adams, 1995).

\section{Establishing Order in a Contested Field}

Current traffic laws are a product of lobbying that sought to privilege the car over other road users. The Royal Automobile Club and the Automobile Association placed advertisements in the front and back covers of the 1931 Highway Code. Similar groups lobbied in the US (Norton, 2008; Vinsel, 2019). Mervyn O'Gorman, the architect of the Highway Code (and vice-chairman of the RAC) preached tolerance for drivers who were speeding and argued for greater control over how pedestrians crossed roads (Moran, 2009). O'Gorman told a Royal Commission, "the whole trouble was that there was no canon of custom" on the road (Moran, 2009, p. 98). In the US, pedestrian fatalities in the 1920s fuelled the contest between local residents and "Motordom" for claims to roadspace (Norton, 2008). Practices once regarded as rude, such as using a horn, came to be accepted as a feature of cars' natural priority. Norton describes how,

\begin{abstract}
"Challenged by an automobile, most people on foot conceded the roadway (including crosswalks) as a matter of practical necessity, leaving aside finer matters of custom, right, or equity. This change in habits lent support to those who claimed that pedestrians did not belong in the streets" (ibid, p. 79).
\end{abstract}

In both the US and UK, it is clear who won. In the US unruly pedestrians were stigmatised as jaywalkers and in 1940s California social scientist Anders (2018/1956) recounted how he was treated as a vagrant simply for not being in a car. Streets, once a space shared by pedestrians and diverse road users, became increasingly mono-cultured as rules and infrastructure were established to facilitate the unobstructed passage of automobiles (Norton, 2008). In the UK, the seeming incompatibility of pedestrians and cars led policy makers in the 1960s to urge that they must be separated (UK Ministry of Transport, 1963). Laws to protect property and discourage street protest led the lawyer Geoffrey Robertson (1993/1963), p. 66) to claim "Cars and horses have more legal rights on the highway than people." The car driver, though, has historically been seen as a special class of person, and politicians have been wary of restraining their rights. The normative presumption in favour of this freedom to drive is itself a forceful factor in the ordering of the road, but one which often conflicts with the formal rules.

The flexibility of rules that allows for drivers to deal with previously unexperienced contingencies also contributes to routine deviance, such as exceeding speed limits (Balendra and Department for Transport, 2021). In 2004, the UK House of Commons Transport Committee conducted an inquiry into traffic law and its enforcement. Its report brimmed with frustration:

\footnotetext{
"The public is rightly outraged at a legal system which considers death or injury as less serious if it has been caused by someone driving a motor vehicle... It is unacceptable that "turning into a minor road and hitting a pedestrian" should be officially classified as careless driving. It is unacceptable that speeding should be seen
}

as unimportant, until such time as death or injury occurs" (House of Commons Transport Committee, 2004; p. 3).

The toll of death and serious injury on the road is indeed high. But any public outrage is not well-reflected in enforcement regimes. When a collision injures or kills someone, the public, the authorities, and the motor industry are more likely to attribute responsibility to driver error than to poor infrastructure, bad laws or flawed technologies (Nader, 1973; Irwin, 1985). The violence itself has been normalised. In Western cultures, driving has come to represent an expression of individual freedom, but it is also, for "law-abiding" citizens, the most likely setting in which they will encounter the police (Seo, 2019). When driving, in control of a powerful machine sold to us on a promise of freedom, the tension with the density of rules and their enforcement is palpable: Crawford (2020) offers a libertarian critique of the legal rules and digital algorithms that constrain his perceived right to drive, which he then extends to attack self-driving cars. The contest between the laws and liberties of the road is played out in the grey areas around some rules. The authorities de facto tolerate a certain amount of speeding, pragmatically judging that it is impossible to completely eradicate it, and they apply the rules with some discretion, e.g., with discretionary margins of error on the registered speed (Ask the Police, 2021).

\section{Technological Ordering}

The first cars emerged onto the existing road network and jostled for space with horse-drawn carriages, pedestrians, public transport systems, and others. Progressively, road infrastructure defined which road users should use which sections of road, and also began to order the movement of vehicles on the road, reducing reliance on costly and overburdened traffic police officers. Explicit road signs and implicit signals communicated by the width, surface and condition of a road provided a material means of ordering road behaviour. An early technological road safety intervention was the "silent policeman": a stationary post placed at the centre of New York City intersections in 1904 to replace their human counterparts in enforcing circulation rules (Norton, 2008, pp. 54-59). In the UK, the "sleeping policeman" is a speed bump. Latour (1994) discusses it as an example of the delegation of responsibility for the enforcement of rules to a device that is devoid of common sense or accountability. The traffic lights that have replaced traffic officers to govern junctions are known in some places, including South Africa, as "robots."

More recent technological ordering includes automated detection and enforcement of speeding using speed cameras and automatic number plate recognition. The installation of speed cameras has resulted in reductions in crashes resulting in death and serious injury by over a third (Gains et al., 2004), and yet their use remains controversial. In France, during the 2018/19 gilets jaunes protests, more than half of the country's speed cameras were vandalised (Crawford, 2020). The 2004 UK House of Commons Transport Committee complained that "Motoring organisations and the press have been quick to criticise local authorities" (p. 3) for over-zealous installation of speed cameras. The proposed introduction of "intelligent speed adaptation (ISA)" technologies in cars aims to encourage 
compliance with speed limits. Based on trials in the UK, Carsten (2012) estimates that an ISA that eliminates virtually all speed limit violations could halve the number of fatal accidents. Public attitudes have been relatively positive, but there is still an expected reluctance from some car owners, even with the promise of insurance discounts (Carsten, 2012). For now, the UK only mandates speed limiters that govern the overall top speed of vehicles, on mopeds, public-service vehicles and heavygoods vehicles, but this is expected to change in 2022 (Hogg, 2019). Some commercial fleets already have limiters to promote institutional policies on fuel economy, environmental protection, and health and safety at work. Other technologies such as ignition interlocks that connect with seatbelts or breathalisers have attracted public antipathy when regulators have sought to encourage rule-following through technological means.

\section{Social Ordering}

The rules of the road, at least in the UK, leave much to interpretation. Indeed, Clause 125 of the Highway Code requires drivers to use their judgement to assess the road conditions and adapt their driving accordingly. The road needs each user to follow the same script as those they interact with, to coordinate movements, avoid potentially disastrous misunderstandings and to fulfil what the Highway Code originally called the "duty to the community" (Ministry of Transport, 1931, p. 3). The communication of intentions becomes vital. In some countries, such as Germany, making eye-contact is encouraged (see Tennant et al., 2015), but in the UK's Highway Code the emphasis is on clear signalling, using indicator lights or arm signals (the latter mainly for cyclists and horse-riders). There is a clear concern that signals can be misinterpreted. For example:

\footnotetext{
"Flashing headlights. Only flash your headlights to let other road users know that you are there. Do not flash your headlights to convey any other message or intimidate other road users" (Highway Code, Rule 110).
}

In some countries (e.g., Italy) the light flash is an alternative to the horn. However, in the UK, this is another provision of the code honoured more in the breach, with road users often flashing headlights to invite others to proceed, or conversely by drivers tailgating others to get those in front to move aside (Parkin et al., 2018). In earlier survey research by one of the authors, $88 \%$ of 8,971 respondents in 15 countries agreed that "there are unwritten rules" (Tennant et al., 2015) and a majority of participants agreed that gestures of thanks or acknowledgement were important and that a commonsensical (see also Latham and Nattrass, 2019) approach was necessary in applying the rules, written or unwritten, to specific stretches of road or specific situations to establish prevailing norms.

Social norms such as gestures, turn-taking and light-flashing may complement laws to create a shared understanding of prosocial conduct on roads. Norms can emerge in response to newly-created laws, new laws can emerge from changing social norms and norms can produce order where law cannot (Ellickson, 1991). In the US, local norms take on names such as the "California Roll" and the "Pittsburgh left." In a dated example, Gregory's (1985) study revealed how Egyptian traffic follows its own grammar. Egyptian drivers exhibited fluid, flexible patterns applicable to the immediate context. Actions like taking unexpected turns, proceeding through red lights late at night, driving on sidewalks, and appealing to other drivers for spatial favours would be considered impudent on Western roads where users rely on stricter notions of who goes where, when, and how. While traffic safety measures differ between driving cultures, the example illustrates how driving cultures can vary in the emphasis placed on explicit laws and implicit norms.

However, the writing and interpretation of rules can also be a source of political conflict. Different road users can follow subtly different scripts. Nattrass (2019) explains how cyclists' bending of and resistance to rules of the road can be a response to perceived injustices. As marginalised road users, they may feel that they must make the road work for them, which justifies occasional acts of transgression. Meanwhile car drivers, who in many places benefit from the current "infrastructural settlement" (ibid p. 5), normalise other forms of deviance while objecting to cyclists' misbehaviour. Christmas and Helman (2011), in their analysis of road users' "private highway code," find that car drivers see cyclists as among the most unsafe road users. Road users apply the rules relevant to the social field of which they are a part. Antagonism between different groups arises as each applies the norms appropriate to the group.

The idealised road is a common platform, offering, in theory, equal access to all (Frischmann, 2012; p. 187). In practice, the playing out of road norms and laws reveals a range of injustices. Rights of way are given and taken unevenly. Pedestrians hurry on crossings even if it is their right of way (Ishaque and Noland, 2008), suggesting a mix of deference and vulnerability. Children are expected and taught to take responsibility for their own safety while drivers are relieved of some of the responsibility for their own mistakes (Schmitt, 2020). Moran (2009) describes how there is a long history of blaming pedestrians for road deaths. One British police officer in 1929 said that in many cases, "the inquest should return a verdict of suicide by the pedestrian" (O'Connell, 1998; p. 140). Improvements in automotive technology provide greater protection to drivers, but greater threats to pedestrians who may be hit by higher, heavier cars (Schmitt, 2020). In some places, drivers of expensive cars are less likely to give way to pedestrians (Coughenour et al., 2020) and drivers are less likely to yield to pedestrians from some racial groups (Goddard et al., 2015).

Even as vehicle use expands in the developing world, there are tentative attempts to push back in Europe. In the UK, many municipalities are reconstituting some streets in favour of cyclists and other forms of sustainable transportation while discouraging the use of private cars (Jones, 2014). In some places, experiments with "living streets" or shared space, are seeking to prioritise pedestrians over traffic, which is slowed down through infrastructures that are designed to make driving less comfortable. Planners are realising that urban streets can be differentiated by their purposes. Streets with a high "Link" function may be designed to optimise travel through an area, while streets with a high "Place" function are primarily destinations in themselves (Jones and Boujenko, 2009). In most 
places, urban streets accommodate not just human drivers and their passengers, but also contend with motorcyclists, pedal cyclists, and pedestrians, not to mention e-scooterists, horses, roller-skaters and skateboarders, or people interchanging from one category to another, as they hop out of a vehicle or dismount their bicycle. Legally, the UK's Highway Code expects these different modes to share the highway: pedestrians should use the pavement (Rule 1) but only a few of the Code's provisions forbid pedestrians from being in or on the road-"you MUST NOT loiter on any type of crossing" (rule 18) and "Pedestrians MUST NOT be on motorways" (Rule 6).

The different layers of order on the road cause ambiguities when rules are inconsistent and contextually variable. For example, an open road may invite faster driving than is permitted by the speed limit. A rule proscribing the flashing of headlights may be transgressed so routinely that the latter becomes a commonly-understood norm. In plural legal systems, a hierarchy is used to resolve inconsistencies and serious disputes may end up in court. The established processes to resolve such matters form another important part of the multi-layered pattern of rules. Given this complexity, how should we consider the arrival of new rules and new codes introduced by new technologies?

\section{RULES FOR HUMAN DRIVING AND SELF-DRIVING}

\section{Whose Rules?}

Current systems of road rules and social norms are layered vertically in different social fields, but they also vary horizontally across road types, places and jurisdictions. In his ethnography of a company developing self-driving vehicles, Stayton (2020) analyses how engineers make sense of aspects of driving that are otherwise tacit or taken-for-granted as they seek to automate a task that humans find easy. McLachlan et al. (2021) propose an approach to order road rules and laws logically so that they can be transparently coded, reducing the scope for the "disorderly" interpretations of common sense. But as Reed et al. (2021) identify, framing the behavioural rules of an AI system so that they align with common sense ethical evaluations of how any situation should be driven is challenging. We should seek to anticipate how, in overlaying digital code onto the road, engineers' attempts to understand the disorder of roads could impose new forms of order, flattening the vertical layers, hardening rules that are currently soft and standardising across places. The imposition of a new logic will not be without controversy.

Arguments for the development of self-driving vehicles are characterised by a form of misanthropy that sees the unevenness and unreliability of human "common sense" as a problem to be solved (Prakken, 2017). Promoters of the technology promise to address the downsides of motoring-accidents, pollution, congestion and economic inefficiency (Mladenović et al., 2020). In particular they foreground the argument that driverless vehicles will avoid the human error that is routinely blamed for a substantial majority of crashes. The focus on removing problematic human features of complex systems that are beyond engineers' control is a familiar pattern (Bainbridge, 1983). Viewed through a lens of automated perfection, human drivers can come to resemble nothing more than "drunk robots" (Sparrow and Howard, 2017). When disasters befall automated systems, whether in planes, cars or in factories, humans often function as a "moral crumple zone" (Elish, 2019). From this view, human driving has normalised "error." The aim of rationalising roads in the name of safety is an attempt to align technology developers' and legislators' interests in the shared project of compliance, but it fails to answer the question of whose rules should rule the road.

The arrival of self-driving vehicles may not be a sudden disruption. It can be seen as part of creeping algorithmism on the road. Some vehicles are already operating with automated driver-assistance systems, and widely-used systems are applying algorithmic logic to traffic prediction and route planning (Fisher, 2020). Technologies such as speed cameras, speed limiters and even speed bumps could be seen in the same way-squeezing the space for discretion. However, if vehicles that drive themselves start to populate the roads, the reconfiguring of the full range of rules-from our normative sense of "good driving" right through to legal injunctions-and responsibilities will be profound. Nyholm and Smids (2020) suggest possible solutions to these challenges: rules could mandate that (a) AVs behave more like human drivers, (b) humans behave more robotically, or (c) humans remain involved in the operations of AVs. However, once we consider the complexity on the road, inside sociotechnical systems and in the transition to new mobility modes, such distinctions look hopeless.

\section{Rules and Responsibilities for Self-Driving}

A number of self-driving technology companies have been working on models intended to contain the task of driving within defined parameters. Examples include Intel Mobileye's Responsibility Sensitive Safety (RSS) (Shalev-Shwartz et al., 2017), Nvidia's Safety Force Field (Nistér et al., 2019) and Aptiv's Rulebooks (Aptiv, 2019). The narrative behind such initiatives often starts with a recognition of the best of human driving: the aim is to capture the common sense rules that define behaviours. For example, a model might, in trying to define a dangerous cutin, set parameters to quantify what would constitute danger when factoring vehicle speeds, road conditions and layout etc. A short promotional video summarises the logic behind the RSS scheme:

"In order to formalise human common sense, Mobileye has
developed the [RSS] model. RSS is an open and transparent model
that uses mathematical models for safe decision making by defining:
what constitutes a dangerous situation, what caused it, and the
proper response to the dangerous situation. By doing so we can
ensure that the Autonomous vehicle will not initiate a dangerous
situation, and also ensure that it responds appropriately when a
dangerous situation is forced upon it by others" (Mobileye, 2018).

The extension of this ideal is that machine drivers might rationalise human drivers even if there is no change to formal rules. Promoters of RSS take this argument further: having formalised common sense so that the unwritten rules are now 
precisely defined, those new rules could become the rules for driving:

\begin{abstract}
"With proper regulatory endorsement, these digitised principles of cautious driving may ultimately become a formal, enforceable and binding contract, thereby mitigating the weakness in the informal social contract today" (Degan, 2019).
\end{abstract}

The homogenisation of "common sense" here obscures the multidimensional heuristics and affordances that characterise road use in different times and places. The model's developers claim that it could be tuned according to local circumstances, laws and driving practices, but the parameters for doing so are narrow. The reference to transparency is because this is a project of safety assurance and persuasion, but the reasons behind the actions of the automated driver would not be completely intelligible. The scripts that the system writes in real time could not be read by a human.

The model's name implies something further: in the event of an accident, an autonomous vehicle operating within the parameters defined by RSS could not have taken decisions that led to the accident. Since the model has codified what it considers the best of human common sense, if a human driver involved in an incident can be shown not to have driven in accordance with those parameters, then that might constitute evidence of responsibility for the incident.

This is not to say that there is only one suggested approach to algorithmic ordering of traffic. Not all companies are so triumphant in their claims to autonomy. Some admit that their system's safe functioning might depend on changes to infrastructure or other road users' behaviour (Tennant and Stilgoe, 2021). While some trumpet autonomous vehicles, others emphasise connected vehicles, communicating with other cars and parts of infrastructure. In 1930s Britain, the Highway Code did not just outline good driving, it also burdened pedestrians with responsibility for their own safety. We have already seen self-driving evangelists argue that pedestrians should behave more predictably or even carry RFID ("radio-frequency identification") tags that would enable sensors to identify them more readily. It is easy to see the flaws with such proposals by asking what would happen in the case of a false negative-a failure to detect an unconnected pedestrian or cyclist-but the definition of such road users as "vulnerable" could mean their exclusion from parts of the road network, much in the same way as pedestrians were formally excluded from motorways and informally disciplined away from other streets with norms and segregatory infrastructure in the 20th Century. Rules for some parts of the network could privilege self-driving, while rules elsewhere allow a diversity of road users and interactions. The attempt to algorithmically resolve conflicts when vehicles interact on the road is likely to generate new conflicts elsewhere. As selfdriving vehicles merge with existing traffic, the extent to which traffic may have to yield to accommodate the new entrants must be debated.

\section{CONCLUSION: COULD CODE COLONISE CONCRETE AND CULTURE?}

The history of roads shows that new technologies do more than just add another player to the game. Depending on the imagined benefits of the new mode, the rules may be rewritten and the field remade to accommodate it, privileging some and burdening others. These changes do more than just rearrange interactions on the road; they also shape lifestyles and places. This was the case with the motor car, particularly in the US but elsewhere too. It could also be the case with self-driving vehicles. In the future, we may find that the benefits of self-driving technology could merit various social adjustments, or we could find that the costs outweigh the benefits. But we should not pretend that a selfdriving car will make a difference to the world's mobility without the world also having to adjust. The price of this adjustment might be worth paying in the name of safety, inclusivity and sustainability, but it needs deliberate discussion. To consider the full range of rules-hard and soft, from multiple sources of authority, with varying legitimacy, mediated by material artefacts and social norms-is to recognise the accommodations the world has made for the motor car. Upgrades to rules have, to a large extent, made the road more legible and navigable for drivers. But the ambiguities of current rules could, for a self-driving car, be disabling.

As automated vehicles take to the streets and promise benefits of safety, efficiency and sustainability, those responsible for infrastructure will come under pressure to make the road more machine-readable, predictable and controllable, whether through digital traffic management or other means (Tennant and Stilgoe, 2021). Digital code could force a reshaping of infrastructures and behaviours to suit self-driving. In practice, this could mean dedicated roadspace, smart infrastructures to digitally connect AVs or demands that pedestrians are more detectable, more alert and more predictable. Shared space, rather than being seen as an interesting experiment in reclaiming streets, could be rejected as an unpredictable inconvenience. Algorithmic logic could dictate the rationalisation of who can move what, when and where, whether through the imposition of rules or economic incentives like road-pricing. Infrastructure investment decisions could follow. In first re-ordering behaviour on the road, code could lead to a reconfiguring of both concrete and culture. If managed well, we could see corrections of some of the worst injustices of car dependence. If done thoughtlessly, injustices could be exacerbated.

Self-driving vehicle technology is still profoundly uncertain. We cannot accurately predict its ramifications. However, we can anticipate that the encoding of rules that are multidimensional and often unwritten will tend toward standardisation. Rules will tend to harden rather than being open to interpretation. Infrastructures, rather than being diverse, polyvalent and open-ended could become more standardised and regulated. Automation raises the possibility of "perfect enforcement" (Zittrain, 2007) of some rules, with instantaneous sanctioning, 
or the prevention of transgressive behaviours in the first place. A technocratic view would see such changes as solutions to longstanding problems of human deviance. And yet car culture prizes the freedom to move, the freedom to be in control and the freedom to transgress, often at the cost of safety. Those dependent upon public transport could see self-driving vehicles as a boon or as undesired competition. Pedestrians may resist attempts to organise their movements, even If those are in the name of their safety. The conflicts could be sharp ones. Technologies can compel, coerce and reject resistance far more effectively than other forms of rule-making. If code does colonise culture and concrete, there is a risk of systemic lock-in. This could resemble car dependence in the 20th century, but it could create added pressures to restrict the freedoms of other modes of transport. Roads, though they are dominated by cars, still occasionally carry horses, penny farthings, street protests and more. A fear of some self-driving critics (e.g., Crawford, 2020) is that increasing automation will put pressure on human driving, which could look dangerous and irresponsible in comparison. In a world of rules made for automated vehicles, we could see calls for a right to drive that

\section{REFERENCES}

Adams, J. (1995). Risk. London: UCL Press.

Akrich, M. (1992). "The de-scription of technical objects," in Shaping Technology/Building Society: Studies in Sociotechnical Change, eds. W. E. Bijker, J. Law (Cambridge, MA: MIT Press), 205-224.

Anders, G. (2018/1956). Die Antiquiertheit des Menschen Bd. I: Über die Seele im Zeitalter der zweiten industriellen Revolution. Munich: C.H. Beck.

Aptiv (2019). Structured AI and Rulebooks. Retrieved from: https://www.aptiv. com/insights/article/structured-ai-and-rulebooks (accessed April 16, 2021).

Ask the Police (2021). Q890: I've Heard That If I Don't Exceed the Speed Limit by a Certain Amount I Won't Be Prosecuted - Is This Correct?

Awad, E., Dsouza, S., Kim, R., Schulz, J., Henrich, J., Shariff, A., et al. (2018). The moral machine experiment. Nature 563, 59-64. doi: 10.1038/s41586-018-0637-6

Bainbridge, L. (1983). Ironies of automation. Automatica. 19, 775-779. doi: 10.1016/0005-1098(83)90046-8

Balendra, P and Department for Transport (2021). Vehicle Speed Compliance Statistics, Great Britain: July - September 2020. Retrieved from: https://assets. publishing.service.gov.uk/government/uploads/system/uploads/attachment_ data/file/955506/vehicle-speed-compliance-statistics- great-britain-july-tosep-2020.pdf (accessed February 10, 2021).

Benda-Beckmann, K. v., and Turner, B. (2018). Legal pluralism, social theory, and the state. J. Legal Plural. Unofficial Law 50, 255-274. doi: 10.1080/07329113.2018.1532674

Björklund, G. M., and Åberg, L. (2005). Driver behaviour in intersections: formal and informal traffic rules. Transp. Res. F Traffic Psychol Behav. 8, 239-253. doi: 10.1016/j.trf.2005.04.006

Bonnefon, J., Shariff, A., and Rahwan, I. (2019). The trolley, the bull bar, and why engineers should care about the ethics of autonomous cars [point of view]. Proc. IEEE 107, 502-504. doi: 10.1109/JPROC.2019.28 97447

Burns, L., and Shulgan, C. (2018). Autonomy: The Quest to Build a Driverlesscar and How It Will Reshape Our World. London: Collins.

Carsten, O. (2012). Is intelligent speed adaptation ready for deployment? Accid. Anal. Prev. 48, 1-3. doi: 10.1016/j.aap.2012.05.012

Christmas, S., and Helman, S. (2011). Road Sharing: Does it Matter What Roads Users think of Each Other? London. resemble current arguments defending the right to bear arms in the US. Our analysis of code, concrete and culture suggests a need for regulators to act now to articulate public interests in future rulemaking, use digital technologies to encourage flexibility rather than exclusivity and resist closure toward single technological options.

\section{AUTHOR CONTRIBUTIONS}

$\mathrm{CT}, \mathrm{CN}$, and JS carried out the detailed research and developed the argument within the paper. GP, PJ, and SM contributed material on specific details as well as review oversight. All authors contributed to the article and approved the submitted version.

\section{FUNDING}

The author(s) disclosed receipt of the following financial support for the research, authorship, and/or publication of this article: Research Councils UK: Economic and Social Research Council, Driverless Futures (ES/S001832/1).

Coughenour, C., Abelar, J., Pharr, J., Chien, L.-C., and Singh, A. (2020). Estimated car cost as a predictor of driver yielding behaviors for pedestrians. J. Transp. Health 16:100831. doi: 10.1016/j.jth.2020.100831

Crawford, M. (2020). Why We Drive: Towards a Philosophy of the Open Road. London: Vintage.

Degan, E. (2019). Intel Editorial: Digitizing the Social Contract for Safer Roads: How Designing an AV Safety Model Enabled Better Safety Solutions for Human Drivers. Retrieved from: https://www.intc.com/news-events/press-releases/ detail/77/intel-editorial-digitizing-the-social-contract-for-safer (accessed April 29, 2021).

Domeyer, J. E., Lee, J. D., Toyoda, H., Mehler, B., and Reimer, B. (2020). Interdependence in vehicle-pedestrian encounters and its implications for vehicle automation. IEEE Trans. Intell. Transp. Syst. 1-13. doi: 10.1109/TITS.2020.3041562

Driving and Vehicle Standards Agency (2018). The OFFICIAL HIGHWAY CODE, 16th Edn., 5th Impression Revised ed. London: Department for Transport.

Elish, M. C. (2019). Moral crumple zones: cautionary tales in human-robot interaction. Engag Sci. Technol. Soc. (2019) 5:21. doi: 10.17351/ests2019.260

Ellickson, R. C. (1991). Order Without Law: How Neighbors Settle Disputes. London: Harvard University Press.

Fish, S. (1984). Fish v. Fiss. Stanford Law Rev. 36, 1325-1347. doi: 10.2307/1228671

Fisher, E. (2020). Do algorithms have a right to the city? Waze and algorithmic spatiality. Cult Stud. 1-22. doi: 10.1080/09502386.2020.1755711

Frischmann, B. M. (2012). Infrastructure: The Social Value of Shared Resources. New York, NY: Oxford University Press.

Gains, A., Heydecker, B., Shrewsbury, J., and Robertson, S. (2004). The NationalSafety Camera Programme-Three-Year Evaluation Report. London: PA Consulting Group.

Goddard, T., Kahn, K. B., and Adkins, A. (2015). Racial bias in driver yielding behavior at crosswalks. Trans. Res. F Traffic Psychol. Behav. 33, 1-6. doi: 10.1016/j.trf.2015.06.002

Gregory, S. W. (1985). Auto traffic in Egypt as a verdant grammar. Soc. Psychol. Q. 48, 337-348. doi: 10.2307/2786695

Hogg, R. (2019). Mandatory Speed Limiters on UK Cars From 2022. Retrieved from: https://www.autotrader.co.uk/content/news/mandatory-speed-limiterson-uk-cars-from-2022 (accessed May 13, 2021).

House of Commons Transport Committee (2004). Traffic Law and its Enforcement. London: House of Commons Transport Committee. 
Irwin, A. (1985). Risk and the Control of Technology: Public Policies for Road Traffic Safety in Britain and the United States. Dover, NH: Manchester University Press.

Ishaque, M. M., and Noland, R. (2008). Behavioural issues in pedestrian speed choice and street crossing behaviour: a review. Transp. Rev. 28, 61-85. doi: $10.1080 / 01441640701365239$

Jones, P. (2014). The evolution of urban mobility: the interplay of academic and policy perspectives. IATSS Res. 38, 7-13. doi: 10.1016/j.iatssr.2014.06.001

Jones, P., and Boujenko, N. (2009). 'Link' and 'Place': a new approach to street planning and design. Road Transp. Res. 18, 38-48. Available online at: https:// search.informit.org/doi/10.3316/informit.738524483157250

Jutras, D. (2001). The legal dimensions of everyday life. Can. J. Law Soc. 16, 45-66. doi: $10.1017 /$ S0829320100006578

Keep, M., and Rutherford, T. (2013). Reported Road Accident Statistics. London: Standard Note, SN/SG/2198.

Latham, A., and Nattrass, M. (2019). Autonomous vehicles, car-dominated environments, and cycling: using an ethnography of infrastructure to reflect on the prospects of a new transportation technology. J. Transp. Geogr. 81:102539. doi: 10.1016/j.jtrangeo.2019.102539

Latour, B. (1988). Mixing humans and nonhumans together: the sociology of a door-closer (written under the name of Johnson, J). Soc. Probl. 35, 298-310. doi: 10.1525/sp.1988.35.3.03a00070

Latour, B. (1992). "Where are the missing masses? The sociology of a few mundane artifacts," in Shaping Technology/Building Society: Studies in Sociotechnical Change, eds. W. E. Bijker, and J. Law (Cambridge, MA: MIT Press), 225-258.

Latour, B. (1994). On technical mediation. Common Knowl. 3, 29-64.

Lessig, L. (2006). Code: Version 2.0, 2nd Edn. New York, NY: Basic Books.

McDermid, J., Koopman, P., Hierons, R., Khastgir, S., Clark, J. A., Fisher, M., et al. (2019). "Certification of highly automated vehicles for use on public roads," in Paper Presented at the ESV 26th Conference (Eindhoven).

McLachlan, S., Neil, M., Dube, K., Bogani, R., Fenton, N., and Schaffer, B. (2021), Smart automotive technology adherence to the law: (de)constructing road rules for autonomous system development, verification and safety. arXiv:2109.02956 [arXiv Preprint]. Available online at: https://arxiv.org/abs/2109.02956

Ministry of Transport (1931). The Highway Code: Issued by the Minister of Transport With the Authority of Parliament in Pursuance of Section 45 of the Road Traffic Act, 1930. London: HMSO.

Mladenović, M. N., Stead, D., Milakis, D., Pangbourne, K., and Givoni, M. (2020). "Chapter ten - governance cultures and sociotechnical imaginaries of selfdriving vehicle technology: comparative analysis of Finland, UK and Germany," in Advances in Transport Policy and Planning, Vol. 5, eds D. Milakis, N. Thomopoulos, and B. van Wee (Academic Press), 235-262.

Mobileye (2018). RSS: Safety Assurance for Automated Vehicles. Retrieved from: https://www.youtube.com/watch?v=EceAB6TUYzo (accessed June 17, 2020).

Moore, S. F. (1973). LAW AND SOCIAL CHANGE: THE SEMI-AUTONOMOUS SOCIAL FIELD AS AN APPROPRIATE SUBJECT OF STUDY. Law Soc. Rev. 7, 719-746. doi: $10.2307 / 3052967$

Moran, J. (2009). On Roads: A Hidden History. Croydon: Profile Books Ltd.

Nader, R. (1973). Unsafe at Any Speed: The Designed-in Dangers of the American Automobile (Expanded Edn.). London: Bantam.

Nattrass, M. (2019). Commonsensical Understandings of Everyday Infrastructures for Cycling in Car Dominated Transport Environments: Rule-Making, RuleBreaking and Social Justification. Doctoral dissertation. University College London. Retrieved from: https://discovery.ucl.ac.uk/id/eprint/10072548/ (accessed February 9, 2021).

Nelken, D. (2008). Eugen ehrlich, living law, and plural legalities. Theor. Inquir. Law 9:6. doi: 10.2202/1565-3404.1193

Nistér, D., Lee, H.-L., Ng, J., and Wang, Y. (2019). An Introduction to the Safety Force Field. Santa Clara, CA. Retrieved from: https://www.nvidia.com/content/ dam/en-zz/Solutions/self-driving-cars/safety-force-field/an-introduction-tothe-safety-force-field-v2.pdf (accessed May 3, 2021).

Norton, P. D. (2008). Fighting Traffic: The Dawn of the Motor Age in the American City. Cambridge, MA: MIT Press.

Nyholm, S., and Smids, J. (2016). The ethics of accident-algorithms for self-driving cars: an applied trolley problem? Ethical Theory Moral Pract. 19, 1275-1289. doi: $10.1007 / \mathrm{s} 10677-016-9745-2$
Nyholm, S., and Smids, J. (2020). Automated cars meet human drivers: responsible human-robot coordination and the ethics of mixed traffic. Ethics Inf. Technol. 22, 335-344. doi: 10.1007/s10676-018-9445-9

O'Connell, S. (1998). The Car in British Society: Class, Gender and Motoring 1896-1939. Manchester; New York, NY: Manchester University Press.

Parkin, J., Clark, B., Clayton, W., Ricci, M., and Parkhurst, G. (2018). Autonomous vehicle interactions in the urban street environment: a research agenda. Proc. Instit. Civ. Eng. Munic. Eng. 171, 15-25. doi: 10.1680/jmuen.16.0 0062

Prakken, H. (2017). On the problem of making autonomous vehicles conform to traffic law. Artif. Intell. Law 25, 341-363. doi: 10.1007/s10506-017-9 210-0

Qian, J. (2014). No right to the street: motorcycle taxis, discourse production and the regulation of unruly mobility. Urban Stud. 52, 2922-2947. doi: 10.1177/0042098014539402

Reed, N., Leiman, T., Palade, P., Martens, M., and Kester, L. (2021). Ethics of automated vehicles: breaking traffic rules for road safety. Ethics Inf. Technol. doi: 10.1007/s10676-021-09614-x. [Epub ahead of print].

Reisman, W. M. (1999). Law in Brief Encounters. New Haven, CT: Yale University Press.

Richardson, H. S. (1999). Institutionally divided moral responsibility. Soc. Philos. Policy 16, 218-249. doi: 10.1017/S0265052500002454

Road Traffic Act (1988).

Robertson, G. (1993/1963). Freedom, the Individual and the Law, 7th Edn. Harmondsworth: Penguin.

Sadik-Khan, J. (2018). Code is the New Concrete [Twitter]. Retrieved from: https:// twitter.com/jsadikkhan/status/1045009194557087749?lang=en (accessed April $12,2021)$.

Schmitt, A. (2020). Right of Way: Race, Class, and the Silent Epidemic of Pedestrian Deaths in America. Washington, DC: Island Press.

Scott, J. C. (1998). Seeing Like a State: How Certain Schemes to Improve the Human Condition Have Failed. New Haven, CT: Yale University Press.

Seo, S. A. (2019). Policing the Open Road: How Cars Transformed American Freedom. Cambridge, MA: Harvard University Press.

Shalev-Shwartz, S., Shammah, S., and Shashua, A. (2017). On a formal model of safe and scalable self-driving cars. arXiv:1708.06374 [arXiv Preprint].

Shove, E. (2012). The Dynamics of Social Practice: Everyday Life and How It Changes. London: SAGE.

Sovacool, B. K., and Hess, D. J. (2017). Ordering theories: typologies and conceptual frameworks for sociotechnical change. Soc. Stud. Sci. 47, 703-750. doi: $10.1177 / 0306312717709363$

Sparrow, R., and Howard, M. (2017). When human beings are like drunk robots: driverless vehicles, ethics, and the future of transport. Transp. Res. C Emerg. Technol. 80, 206-215. doi: 10.1016/j.trc.2017.04.014

Stayton, E. (2020). Humanizing Autonomy: Social Scientists' and Engineers' Futures for Robotic Cars. Doctoral dissertation. Massachusetts Institute of Technology.

Stilgoe, J. (2018). Machine learning, social learning and the governance of self-driving cars. Soc. Stud. Sci. 48, 25-56. doi: 10.1177/0306312717 741687

Stilgoe, J. (2021). How can we know a self-driving car is safe? Ethics Inf. Technol. doi: 10.1007/s10676-021-09602-1. [Epub ahead of print].

Svenson, O. (1981). Are we all less risky and more skillful than our fellow drivers? Acta Psychol. 47, 143-148. doi: 10.1016/0001-6918(81)90 005-6

Tennant, C., Stares, S., Howard, S., Hall, M., Franks, B., and Bauer, M. (2015). Research Project on Driver Behaviour: Report submitted by LSE Enterprise to Goodyear. London. Retrieved from: http://www.lse.ac.uk/business-andconsultancy/consulting/consulting-reports/the-ripple-effect- of-driversbehaviour-on-the-road (accessed December 11, 2015).

Tennant, C., and Stilgoe, J. (2021). The attachments of 'autonomous' vehicles. Soc. Stud. Sci. doi: 10.1177/03063127211038752. [Epub ahead of print].

UK Ministry of Transport (1963). Traffic in Towns: A Study of the Long Term Problems of Traffic in Urban Areas. London: HMSO.

Urry, J. (2004). The 'System' of automobility. Theory Cult. Soc. 21, 25-39. doi: $10.1177 / 0263276404046059$ 
Van Lente, H. (2000). From Promises to Requirement. Contested Futures: A Sociology of Prospective Techno-Science. Aldershot: Ashgate.

Vinsel, L. (2019). Moving Violations. Baltimore: The John Hopkins University Press.

Wetmore, J. M. (2003). Driving the dream, The history and motivations behind 60 years of automated highway systems in America. Autom. Hist. Rev. 7, 4-19.

Winner, L. (1977). Autonomous Technology: Technics-Out-of-Control as a Theme in Political Thought. Boston, MA: MIT Press.

Wynne, B. (1988). Unruly technology: practical rules, impractical discourses and public understanding. Soc. Stud. Sci. 18, 147-167. doi: $10.1177 / 030631288018001006$

Young, H. P. (1996). The economics of convention. J. Econ. Perspect. 10, 105-122. doi: $10.1257 /$ jep.10.2.105

Zittrain, J. L. (2007). “Perfect enforcement on tomorrow's internet," in Regulating Technologies: Legal Futures, Regulatory Frames and Technological Fixes Oxford and Portland, eds. R. Brownsword, and K. Yeung (Or: Hart), 125-126.
Conflict of Interest: The authors declare that the research was conducted in the absence of any commercial or financial relationships that could be construed as a potential conflict of interest.

Publisher's Note: All claims expressed in this article are solely those of the authors and do not necessarily represent those of their affiliated organizations, or those of the publisher, the editors and the reviewers. Any product that may be evaluated in this article, or claim that may be made by its manufacturer, is not guaranteed or endorsed by the publisher.

Copyright (c) 2021 Tennant, Neels, Parkhurst, Jones, Mirza and Stilgoe. This is an open-access article distributed under the terms of the Creative Commons Attribution License (CC BY). The use, distribution or reproduction in other forums is permitted, provided the original author(s) and the copyright owner(s) are credited and that the original publication in this journal is cited, in accordance with accepted academic practice. No use, distribution or reproduction is permitted which does not comply with these terms. 